\title{
CONTRATAÇÃO POR DESEMPENHO EM SERVIÇOS DE MANUTENÇÃO: O CASO DA CST ARCELOR BRASIL
}

\section{PERFORMANCE CONTRACTING OF MAINTENANCE SERVICES: THE CASE OF CST ARCELOR BRAZIL}

\author{
Cristina Weber Ambrósio \\ Engenheira, Mestranda em Engenharia de Produção \\ Universidade Federal da Paraíba \\ Programa de Pós-Graduação em Engenharia de Produção \\ Rua Dom Pedro II, 485 - Glória, Vila Velha \\ Tel. (27) 3348-2487 - cweber@terra.com.br \\ Maria Silene Alexandre Leite, Dsc \\ Doutora em Engenharia de Produção \\ Universidade Federal da Paraíba \\ Programa de Pós-Graduação em Engenharia de Produção \\ Caixa Postal 5045 - Cidade Universitária, Bloco G, Centro de Tecnologia \\ Tel. (83) 3216-7813 - leite@ct.ufpb.br
}

\begin{abstract}
RESUMO
O objetivo deste artigo é discutir a contratação por desempenho e os benefícios que ela pode proporcionar para as empresas. $\mathrm{O}$ trabalho apresenta o processo de contratação por avaliação de desempenho na terceirização de serviços de manutenção. A contribuição do artigo consiste em identificar os fatores motivadores desta modalidade de contrato, bem como as etapas recomendadas para a obtenção de sucesso em um processo de contratação desta natureza. É apresentado o estudo de caso da siderúrgica CST Arcelor Brasil, onde se utiliza o modelo de contratação por desempenho na área de serviços de manutenção. Os contratos são firmados com base em cláusulas de desempenho, que buscam monitorar a performance dos serviços prestados segundo indicadores estabelecidos pela CST em conjunto com empresas parceiras. A metodologia utilizada consiste na pesquisa bibliográfica sobre a evolução das relações com fornecedores e em entrevistas com especialistas nas áreas de contratação, logística e vendas.
\end{abstract}

Palavras-chave: Contratação por Desempenho, Parceria, Manutenção. 


\begin{abstract}
This article aims at discussing performance contracting and the benefits is can provide to the companies. This research is about performance contracting process in maintenance services outsourcing. This article contributes identifying the positive aspects of this kind of contracting, so as the steps recommended to a successful implementation of contracts of this nature. The Case of CST Arcelor Brazil is presented, where performance contracting is used for maintenance services. Contracting is done based on performance clauses, which monitor services according to performance indicators established by CST and its partners. The methodology used consists on bibliographic research about the evolution of relationships with suppliers and interviews with specialist in sales, logistics and contracting.
\end{abstract}

Key-words: Performance Contracting, Partnership, Maintenance.

\title{
INTRODUÇÃO
}

A necessidade de integração e cooperação entre os elos de uma cadeia de suprimentos tem sido amplamente ressaltada nos últimos anos. Conforme o grau de comprometimento e formalização, são estabelecidos diferentes tipos de relacionamentos entre empresas de uma cadeia de suprimentos, tal como a parceria.

No contexto atual, além de se ter uma integração dos processos com a estratégia competitiva de uma empresa, é preciso também integrar processos internos chaves com fornecedores e clientes. Nos anos 90, em setores industriais mais competitivos, as demandas do mercado levaram muitas empresas a concentrar esforços em suas atividades principais, deixando a cargo de fornecedores os processos auxiliares (PIRES, 2004).

O setor de manutenção de uma empresa constitui, atualmente, uma área estratégica, devido aos ganhos que é capaz de proporcionar quando bem gerenciada (SOUZA, 2005). A tradição da manutenção em adquirir serviços de empresas terceiras torna importante o processo de contratação para o seu bom funcionamento. A utilização da terceirização como ferramenta gerencial estratégica busca maximizar a disponibilidade dos equipamentos produtivos. A evolução da contratação de serviços em manutenção tem apontado para o modelo baseado na avaliação de desempenho junto a empresas parceiras (SILVA, 2006). 


\section{METODOLOGIA}

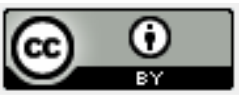

Para a elaboração deste artigo realizou-se uma pesquisa bibliográfica sobre a evolução das relações entre fornecedores e contratantes, desde o surgimento da terceirização até as atuais tendências de estabelecimento de relações de parceria e de elaboração de contratos baseados em cláusulas de desempenho. Foram consultados trabalhos acadêmicos sobre estes assuntos, para que fosse obtido o embasamento teórico necessário à elaboração do artigo. O conhecimento sobre contratação por desempenho em serviços de manutenção foi obtido através de pesquisas em artigos apresentados em congressos especializados na área de manutenção.

Com o intuito de complementar o conhecimento prático sobre contratação por desempenho, foram realizadas entrevistas com especialistas da CST Arcelor Brasil nas áreas de logística, vendas e contratação de manutenção. As informações obtidas através destas entrevistas, bem como em artigos apresentados pela CST em congressos de manutenção, forneceram subsídios para que fosse realizado o estudo de caso na CST Arcelor Brasil.

Através da análise das informações obtidas, foi possível identificar a sequiência de etapas recomendadas para o processo de formalização de contratação por desempenho, bem como as vantagens obtidas pelas empresas através desta forma de contratação.

\section{TERCEIRIZAÇÃO}

A contratação de serviços de terceiros há muito vem sendo utilizada. Nos Estados Unidos, começou a ser praticada na década de 40, durante a Segunda Guerra Mundial, e se intensificou no Brasil nos anos 90, em virtude da abertura de mercado (HALEN, 2000). Inicialmente, terceirizar significava apenas contratar mão-de-obra para a realização de atividades de apoio. O conceito de terceirização evoluiu, passando a ser considerado um processo de gestão pelo qual se repassam algumas atividades para terceiros, com os quais se estabelece uma relação de parceria. Assim, a empresa contratante concentra-se em suas atividades fins, tornando-se mais ágil e competitiva, e transfere atividades de apoio para empresas especialistas em tais atividades (SÉDER, 2002).

Para que seus objetivos sejam alcançados, a terceirização deve ser implementada através de um processo eficaz de contratação de serviços, capaz de atender aos anseios de 
todos os envolvidos no processo (SÉDER, 2002). A terceirização deve ser encarada como parte da cadeia de suprimentos, permitindo uma maior especialização dentro da cadeia e, consequientemente, um aumento na velocidade e flexibilidade das respostas à demanda (PIRES, 2004).

3. A terceirização da manutenção baseada em relações de parceria surgiu no Brasil por volta de 1995, sendo ainda hoje objeto de discussão quanto à qualidade das relações de parceria reais e desejadas (PINTO, 2004). Inicialmente, a terceirização da manutenção ocorreu sob condições contrárias ao conceito de parceria, sendo denominada empreiteirização. O relacionamento entre as empresas caracterizava-se pela obtenção de vantagens unilaterais, decisões baseadas apenas em preço e descomprometimento gerencial da contratada. Atualmente, uma parcela do mercado já reconhece que só faz sentido terceirizar a manutenção quando se agrega valor à empresa ou ao processo, o que se obtém através de parcerias.PARCERIAS ESTRATÉGICAS

O ponto-chave do conceito de terceirização, segundo Halen (2000), está na construção de parcerias sólidas e legítimas, priorizando o equilíbrio de forças. $\mathrm{O}$ estabelecimento de parceria entre empresas possibilita a construção de uma cadeia de qualidade na qual todos precisam contribuir para a melhoria dos resultados do empreendimento. Os objetivos de médio e longo prazo a serem atingidos através da adoção da parceria devem ser bem definidos (SÉDER, 2002).

Relacionamentos de parceria são acordos cooperativos duradouros entre empresas, envolvendo fluxos e ligações que usam recursos ou estruturas de governança de organizações autônomas, para a realização conjunta de metas individuais associadas à missão corporativa de cada empresa patrocinadora (SLACK, 2002). Desta forma, o sucesso ou fracasso será de todos que participam direta ou indiretamente da cadeia (SILVA, 2006).

A partir do estabelecimento de um ambiente estratégico, com o mapeamento de metas, objetivos, missão, visão e diretrizes da empresa, torna-se igualmente estratégica a decisão pela terceirização de serviços baseada no conceito de parceria (HALEN, 2000). A CST Arcelor Brasil, cuja missão se apóia em valores e políticas corporativas, reconheceu na parceria com fornecedores de serviços de manutenção uma estratégia para maximizar a estabilidade da produção e reduzir a variabilidade do processo, como indicado na figura 1. 


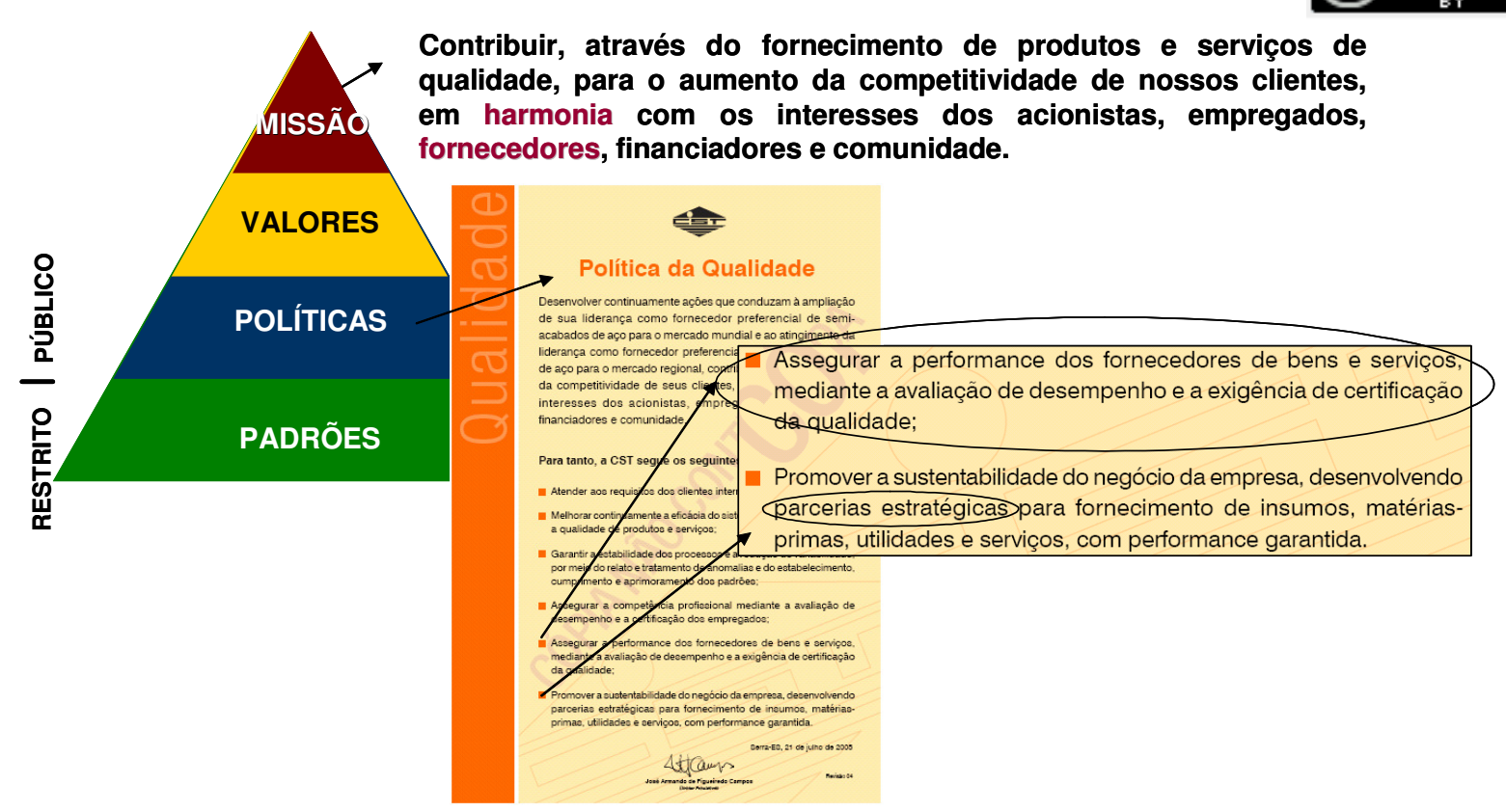

Figura 1: Missão e Política da Qualidade da CST Arcelor Brasil

Fonte: Santos (2005, p.3)

A figura 2 mostra a cadeia de suprimentos da CST Arcelor Brasil, na qual são apresentadas as integrações dos principais processos que produzem produtos e serviços. A cadeia de suprimentos deve agregar valor a todos os envolvidos. Segundo esta ótica, as relações de parcerias estratégicas entre a CST e alguns fornecedores estão nos elos da cadeia destacados na figura 2, tais como os relacionamentos com fornecedores de materiais refratários, materiais gerais e de serviços de manutenção. 


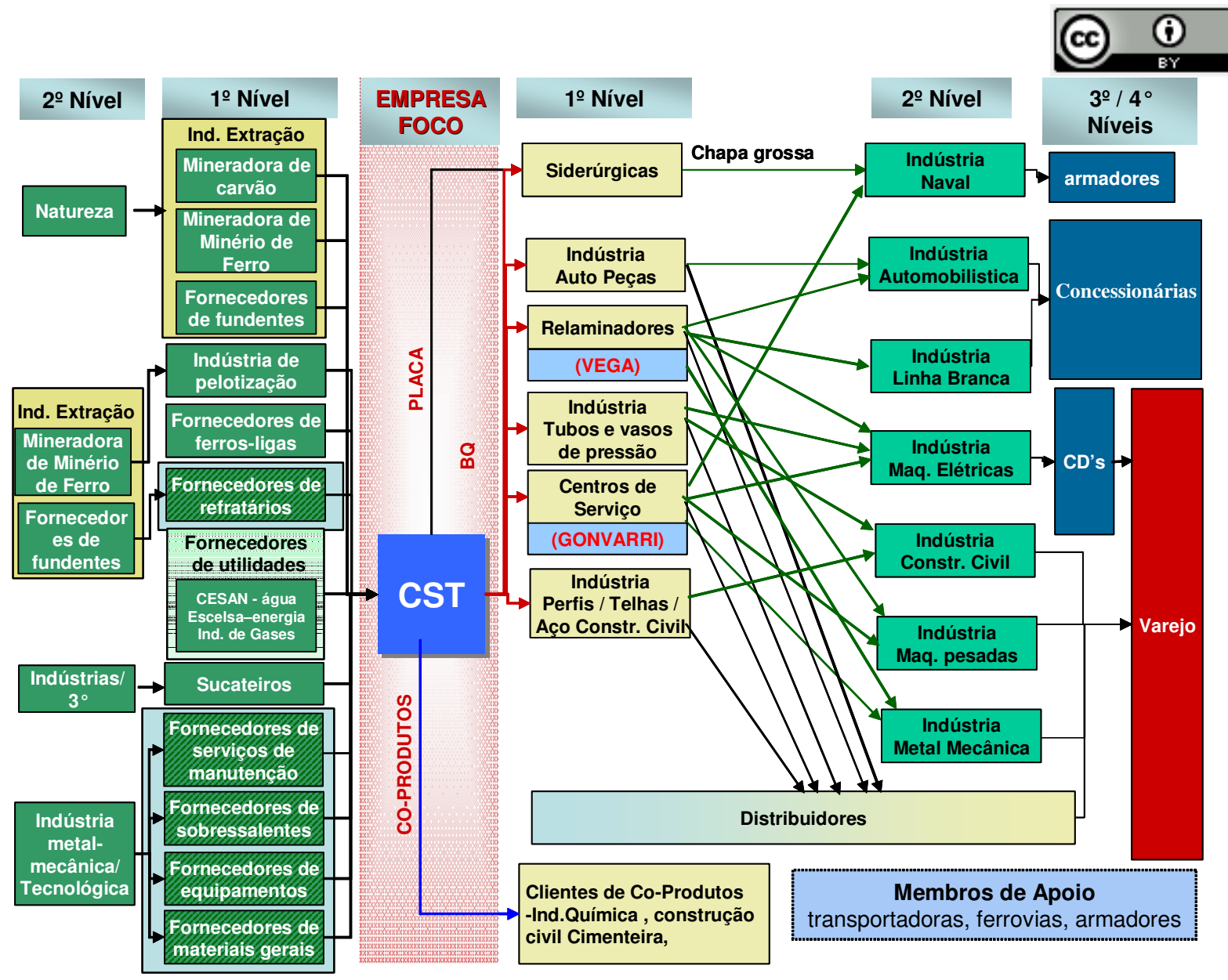

Figura 2: Cadeia de Suprimentos da CST Arcelor Brasil

Fonte: CST Arcelor Brasil

O conceito ideal de terceirização da manutenção envolve o desenvolvimento de relações de efetiva parceria em busca de menores custos e maior qualidade, através de uma política de ganhos mútuos e de contratação não apenas de atividades, mas de soluções (PINTO, 2004). Em relações de parceria, os custos não são repassados, mas administrados pelos parceiros, e sua redução advém dos resultados de produtividade e qualidade (PEDRIALI, 2004). No quadro 1, é apresentado uma comparação das características de um fornecedor usual em relação a um parceiro.

\begin{tabular}{|l|l|}
\hline \multicolumn{1}{|c|}{ Fornecedor } \\
\hline Desconfiança/Medo dos riscos & Confiança \\
\hline Levar vantagem em tudo & Política do "ganhar aos poucos" \\
\hline Ganhos de curto prazo & Economia de escala \\
\hline Pluralidade de fornecedores & Fornecedor único para a atividade terceirizada \\
\hline O preço decide & Enfoque na qualidade \\
\hline Antagonismo & Cooperação \\
\hline Postura reativa & Postura Criativa \\
\hline Fornecedor como adversário & Fornecedor como sócio \\
\hline
\end{tabular}

Quadro 1: Mudanças no relacionamento com fornecedores

Fonte: Pedriali (2004, p.4) 
A parceria deve buscar objetivos pré-definidos, onde contratante e contratada ganhem com a melhoria dos resultados, através de contratos por desempenho. (SOUZA, 2005). A relação que se busca é de cumplicidade, baseada não somente na execução de atividades, mas também na gestão e no risco do negócio (SILVA, 2006).

\section{CONTRATAÇÃO POR DESEMPENHO NO SETOR DE MANUTENÇÃO}

A partir dos crescentes níveis de terceirização da manutenção, tornou-se necessária a busca por formas mais adequadas de se conduzir as relações entre contratante e contratada. Inicialmente, estas relações não envolviam sequer o conceito de parceria, tendo evoluído para relações baseadas no estabelecimento de metas comuns com ênfase no desempenho das plantas industriais, a ser monitorado através do acompanhamento de indicadores previamente definidos (SORMANI, 2005).

O contrato é a principal ferramenta de monitoramento das relações de parceria (SÉDER, 2002). O contrato de parceria, além de proteger legalmente os envolvidos na execução das atividades, constitui um documento para a gestão adequada dos mesmos. Atualmente, a contratação de serviços de manutenção é praticada nas modalidades de mão-deobra, serviços e desempenho, as quais surgiram evolutivamente ao longo dos anos, sendo a contratação baseada em desempenho a mais recente e inovadora.

$\mathrm{Na}$ contratação por desempenho contratante e contratado são parceiros, e têm foco no desempenho dos equipamentos. A disponibilidade dos equipamentos constitui um critério de remuneração pela prestação dos serviços e recompensa vantajosamente as partes envolvidas (PINTO, 2004). Neste tipo de contrato, são definidos indicadores que mensuram a evolução quantitativa do desempenho dos equipamentos e sistemas, tais como índice de disponibilidade de equipamento e tempo médio entre falhas do sistema.

Ao se atingir as metas de desempenho e disponibilidade, a contratada terá maior lucro, ainda que a demanda por serviços diminua, pois o recurso não despendido é dividido entre as partes (SORMANI, 2005). Outras características deste tipo de contrato são: compartilhamento de lucro, implementação de soluções, contrato de longo prazo, relacionamento de parceria, cumprimento de metas negociadas e responsabilidade técnica totalmente da contratada. 


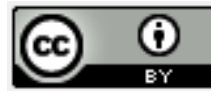

As principais vantagens da contratação por resultados são: redução de custos com serviços de manutenção, maior disponibilidade e produtividade das plantas industriais, aumento da vida útil dos equipamentos, diminuição de custos com materiais, maior autonomia da contratada, compartilhamento da aquisição de conhecimento e de responsabilidades (SILVA, 2006).

\subsection{Indicadores de desempenho}

A busca pela melhoria de desempenho em empresas de classe mundial é apoiada por indicadores capazes de quantificar e acompanhar processos, eliminando a subjetividade e facilitando a tomada de decisões corretas. A contratação por desempenho na manutenção prevê a utilização de indicadores que visam estabelecer, em comum acordo, os objetivos a serem alcançados. Os indicadores acompanham os principais processos da manutenção, e devem ser selecionados de forma a medir a eficácia destes processos. Uma vez atendidas ou superadas as metas estabelecidas no contrato, a contratada pode receber bonificação, ou, em caso contrário, ser penalizada através de ônus.

Os gestores devem selecionar os indicadores adequados a cada processo e em conformidade com o planejamento estratégico da organização (SORMANI, 2005). Indicadores relacionados à segurança, meio-ambiente e saúde são indispensáveis. Algumas técnicas de análise comparativa e ponderação de indicadores auxiliam nesta seleção.

Os indicadores podem ser classificados como indicadores meio ou de resultados. Os indicadores meio medem fatores que mostram a tendência do indicador de interesse ou indicam se os meios necessários estão sendo providos. Como exemplos deste tipo de indicador têm-se: tempo médio entre falhas, tempo médio para reparo e atendimento ao plano de manutenção preventiva. Os indicadores de resultados medem os resultados nos quais se está interessado, tais como disponibilidade e confiabilidade do equipamento.

Pinto (2004) exemplifica alguns indicadores, classificando-os em: indicadores de confiabilidade - número de acidentes, índice de absenteísmo, porcentagem de realizações de ações de segurança, saúde e meio-ambiente; indicadores de custo - número de horas-extras, faturamento por horas trabalhadas da contratada; indicadores de qualidade - satisfação com a contratada no que se refere a prazo, qualidade, segurança, capacidade técnica e iniciativa. $\mathrm{O}$ 
quadro 2 apresenta alguns exemplos de indicadores, agrupados segundo o objetivo a eles relacionados.

\begin{tabular}{|l|l|}
\hline \multicolumn{1}{|c|}{ Objetivo } & \multicolumn{1}{c|}{ Indicadores } \\
\hline $\begin{array}{l}\text { Qualidade do serviço de } \\
\text { manutenção }\end{array}$ & $\begin{array}{l}\text { - Tempo médio entre falhas } \\
\text { - Índice de falhas após a manutenção } \\
\text { - Índice de re-trabalho } \\
\text { - Tempo médio para realização de reparo }\end{array}$ \\
\hline $\begin{array}{l}\text { Produtividade de equipamentos e } \\
\text { sistemas }\end{array}$ & $\begin{array}{l}\text { - Disponibilidade do equipamento } \\
\text { - Cumprimento do plano de manutenção preventiva } \\
\text { - Vida útil do equipamento } \\
\text { - Confiabilidade do equipamento }\end{array}$ \\
\hline $\begin{array}{l}\text { Segurança e Saúde de } \\
\text { empregados e contratados }\end{array}$ & $\begin{array}{l}\text { - Número de acidentes } \\
\text { - Índice de absenteísmo }\end{array}$ \\
\hline - Índice de realizações de ações de segurança e saúde \\
\hline $\begin{array}{l}\text { Eliminação de Impactos ao } \\
\text { Meio-Ambiente }\end{array}$ & $\begin{array}{l}\text { Índice de ocorrências ambientais ocasionadas por } \\
\text { manutenções }\end{array}$ \\
\hline $\begin{array}{l}\text { Capacitação técnica de } \\
\text { Mão-de-Obra }\end{array}$ & $\begin{array}{l}\text { - Porcentagem de empregados da contratada com } \\
\text { certificação em manutenção }\end{array}$ \\
\hline Redução de custos & $\begin{array}{l}\text { - Fúmero de horas-extras trabalhadas pela contratada } \\
\text { - Propostas de redução de custos aceitas pela contratante }\end{array}$ \\
\hline
\end{tabular}

Quadro 2: Exemplos de Indicadores de performance

Fonte: Adaptado de Pinto (2004, p.5)

\subsection{Etapas da contratação por desempenho}

Ao se optar pela contratação por desempenho, é importante identificar as atividades adequadas a este modelo de contratação. Deve-se ter um bom histórico recente de contratação destas atividades, assim como indicadores representativos dos serviços envolvidos nestas atividades. É igualmente importante a seleção de empresas capazes de estabelecer parcerias. 
De acordo com Sormani (2005), para a obtenção de sucesso, é recomendável a utilização de algumas etapas no processo de implantação da contratação por desempenho, tais como:

- Constituição de uma equipe multi-disciplinar, responsável por planejar e implantar o processo de transição de contratos convencionais para contratos por desempenho, identificando as atividades apropriadas a este tipo de contratação;

- Verificação da compatibilidade da contratação por desempenho das atividades selecionadas com o planejamento estratégico e missão da empresa;

- Definição de soluções compatíveis com a realidade da empresa e do mercado fornecedor;

- Seleção de indicadores representativos do desempenho dos serviços a serem contratados. Os indicadores devem ser alcançáveis e de fácil entendimento e medição;

- Elaboração de especificação detalhada do contrato, estabelecendo-se um modelo de remuneração claro e objetivo e que incentive a eficácia das ações do contratado;

- Seleção de empresas qualificadas e parceiras na busca de soluções;

- Gerenciamento e acompanhamento do desempenho da contratada, com foco na análise de resultados, relacionamento de longo prazo e avaliações periódicas.

De modo geral, a equação de remuneração por resultados consiste em (SORMANI, 2005):

Valor da remuneração $(\mathrm{VR})=$ Parcela Fixa $(\mathrm{PF})+$ Parcela Variável $(\mathrm{PV})$

Onde: Parcela Variável $(\mathrm{PV})=$ Parcela Fixa(PF) $x$ Fator de Performance (FP)

Fator de Performance $(F P)=$ FP1 $x$ FP2 $\times$ FP3 $x \ldots$

Onde: Fator de Performance (FP) é associado a indicadores de desempenho.

Segundo Garcia (2005) alguns dos sistemas de remuneração por desempenho praticados são:

- Pagamento de remuneração variável definida por percentual sobre o valor do contrato;

- Pagamento de percentual sobre o faturamento adicionado à contratante em função de ações implementadas pelo fornecedor;

- Rateio da margem de contribuição sobre a produção agregada pelo contrato; 
- Divisão entre contratante e contratado do valor correspondente ao custo direto de materiais e serviços que o contrato de manutenção conseguir reduzir.

\section{ESTUDO DE CASO NA CST ARCELOR BRASIL}

A Companhia Siderúrgica de Tubarão - CST Arcelor Brasil é uma usina siderúrgica localizada no município da Serra, Estado do Espírito Santo, e produz anualmente 5 milhões de toneladas de aço. Inaugurada em 1983, está localizada em uma área de 13,5 milhões de metros quadrados, com infra-estrutura logística que favorece a disponibilidade de matériasprimas e o transporte de produtos para atendimento aos mercados interno e externo.

A manutenção na CST Arcelor Brasil tem função estratégica, sendo sua missão garantir a estabilidade do processo de produção, reduzindo a sua variabilidade e contribuindo para a perenização da empresa. Desta forma, o objetivo da manutenção é obter a confiabilidade dos equipamentos, evitando perdas financeiras (SANTOS, 2005).

Seguindo orientações do plano empresarial, a manutenção deve ser executada por empresas parceiras, permanecendo a cargo da CST apenas as atividades estratégicas, conforme figura 3. Através das parcerias, busca-se maximizar a utilização dos ativos da empresa pela gestão da manutenção por confiabilidade (SANTOS, 2005). Para tanto, as empresas parceiras são selecionadas com base em especialização e os contratos firmados são de longo-prazo, com cláusulas de desempenho, seguindo as diretrizes da Política de Qualidade. Os pilares da manutenção são formados pela inspeção preventiva de equipamentos e pelo planejamento, programação e controle das intervenções. Estas atividades são realizadas pela CST, assim como o gerenciamento de empresas parceiras, responsáveis pela execução da manutenção. 


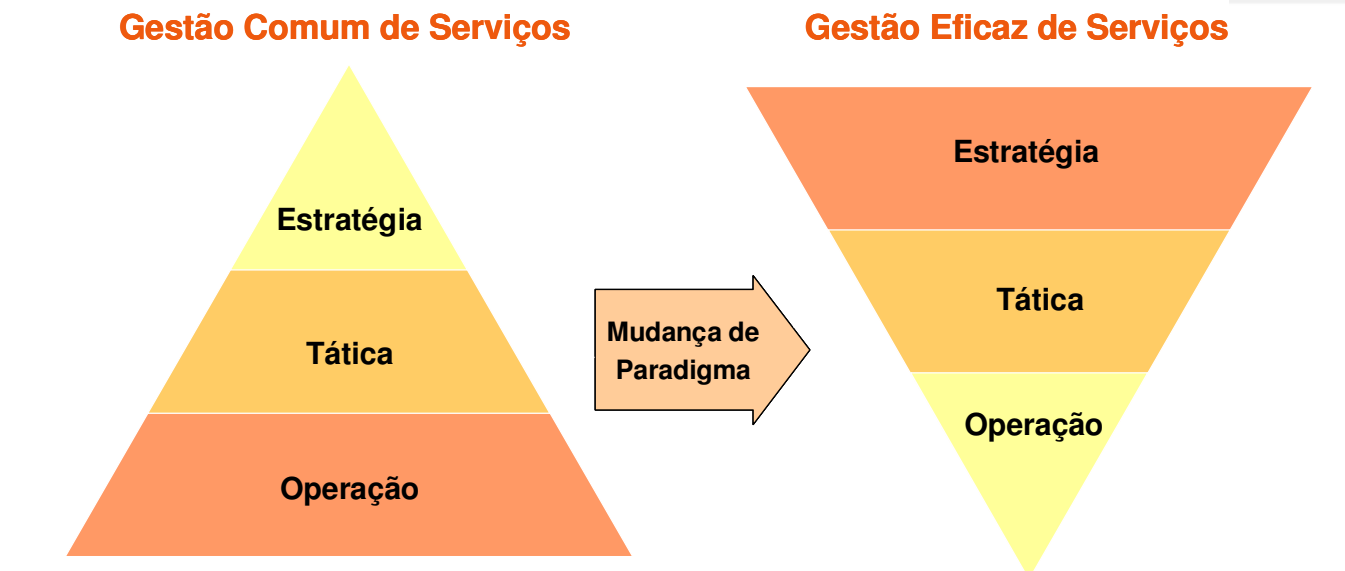

- Foco nas ações tático-estratégicas, e não nas atividades puramente operacionais.

Figura 3: Gestão eficaz de serviços

Fonte: CST Arcelor Brasil

\subsection{Evolução da contratação na CST Arcelor Brasil}

Cerca de 99\% dos contratos firmados pela CST até 2000 eram baseados em homemhora ou preço unitário. A partir desta data, os contratos de manutenção começaram a evoluir para contratos a preço global, para os casos de manutenção em paradas programadas. A partir de 2004, todas as manutenções de conjuntos, tais como bombas, válvulas, cilindros hidráulicos, dentre outros, passaram a ter que ser feitas fora da área de produção, o que impulsionou os contratos em parceria com empresas de manutenção. Como vantagem, as intervenções passaram a ser executadas em oficinas especializadas, em condições adequadas para serviços e testes, evitando a inserção de defeitos diretamente no ambiente de produção.

Em 2005, 60\% dos contratos de manutenção já eram feitos com cláusulas de desempenho. Como meta, até o final de 2006, todos os contratos permanentes e estratégicos devem incluir este tipo de cláusula, visando alinhar parceiras na busca da maximização da disponibilidade e confiabilidade operacional e minimização de acidentes e danos ambientais (SANTOS, 2005).

\subsection{Contratação por performance no setor de manutenção da CST Arcelor Brasil}

A CST Arcelor Brasil, como desdobramento de suas políticas corporativas de qualidade, saúde e ambiental, adotou a contratação por desempenho em consonância com as 
orientações estratégicas para a área de manutenção, baseadas no desenvolvimento de parcerias, aumento da estabilidade operacional, prolongamento de vida útil dos equipamentos, atualização tecnológica, minimização dos impactos ambientais e segurança e saúde de empregados e contratados. Este modelo de contratação possibilitou à CST concentrar suas habilidades em sua atividade fim, que é a fabricação do aço, permitindo delegar para terceiros atividades meio, nas quais estas empresas são especializadas. Alguns fatores contribuíram para o sucesso da contratação por desempenho na CST:

- A Política de Qualidade da empresa incentiva a contratação por desempenho;

- Apoio e incentivo a qualificação e certificação de empresas parceiras;

- Utilização de modelo descentralizado de contratação de serviços, agilizando e flexibilizando este processo;

- Utilização de matriz de categorização de fornecedores para identificação de oportunidades de contratação de parceiros, conforme figura 4.

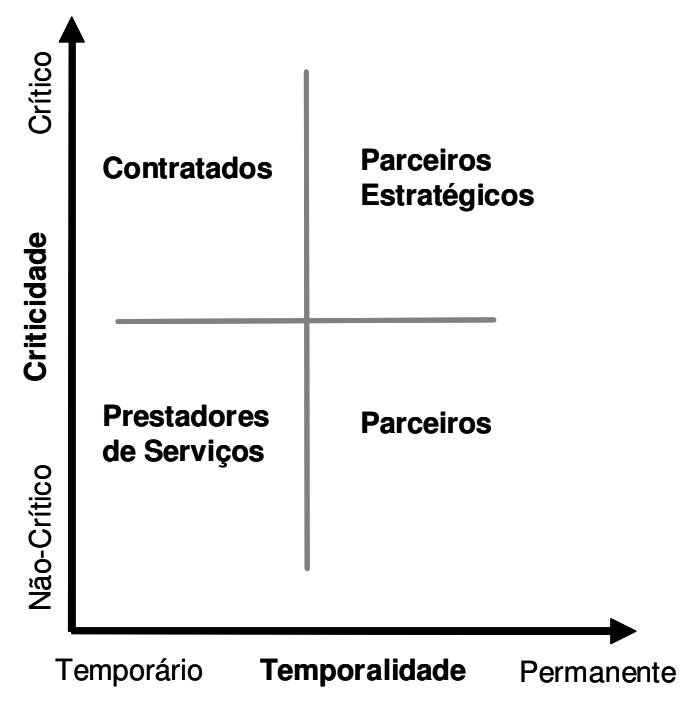

Figura 4: Matriz de categorização de fornecedores

Fonte: Santos (2005, p.5)

A cada demanda por serviços, o órgão gestor deve analisar a viabilidade operacional e estratégica de terceirização. Em geral, conforme mostrado na figura 4, serviços críticos e de longa duração apontam para a contratação de parcerias, com acompanhamento de resultados. É importante que o serviço a ser contratado por desempenho tenha seu escopo bem definido e 


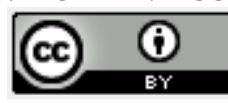

um histórico dos índices de homem-hora e preço unitário por atividade bem definidos. É recomendado que se conheça os resultados a serem alcançados. Desta forma, a definição dos indicadores de desempenho torna-se mais fácil, o que contribui para a eficácia da contratação e comprometimento do contratado. Quando não se tem domínio sobre a natureza dos indicadores, pode-se recorrer a empresas especializadas.

A seleção de parceiros tem como requisitos a especialização e certificação de qualidade das empresas, cuja mão-de-obra deve ser treinada e certificada. Também são avaliadas as soluções tecnológicas apresentadas e a equipe de engenharia e planejamento destas empresas, assim como sua condição financeira e aspectos trabalhistas. No quadro 3, são apresentadas as etapas da contratação por desempenho adotadas pela CST Arcelor Brasil (SANTOS, 2005).

\begin{tabular}{|c|l|}
\hline Fluxo do Processo & \multicolumn{1}{c|}{ Etapas } \\
\hline Planejamento & $\begin{array}{l}\text { - Avaliação da indicação de contratação por desempenho do serviço. } \\
\text { - Avaliação do mercado fornecedor de serviços. }\end{array}$ \\
\hline \multirow{5}{*}{ Contratação } & $\begin{array}{l}\text { - Visitas técnicas a possíveis parceiros. } \\
\text { - Pré-qualificação de empresas. } \\
\text { - Emissão de cartas-convite. } \\
\text { - Recebimento e avaliação de propostas técnicas e comerciais. } \\
\text { - Elaboração de relatório técnico-comercial, recomendando a contratação da } \\
\text { empresa. } \\
\text { - Elaboração detalhada do contrato, incluindo cláusulas de desempenho. } \\
\text { - Definição de cláusulas de desempenho, estabelecendo resultados e metas a } \\
\text { serem alcançados ou superados, com destaque para: } \\
\text { - definição de indicadores de desempenho } \\
\text { - definição de periodicidade de acompanhamento } \\
\text { - estabelecimento de critérios para pagamento de bônus ou onûs. }\end{array}$ \\
\hline \multirow{3}{*}{ Gerenciamento } & $\begin{array}{l}\text { - Reunião de mobilização. } \\
\text {-Acompanhamento periódico dos serviços, com avaliação de desempenho. } \\
\text { - Notificação de irregularidades. }\end{array}$ \\
\hline
\end{tabular}

Quadro 3: Etapas da contratação por desempenho na CST Arcelor Brasil

Fonte: SANTOS (2005, p.8)

Alguns indicadores utilizados e seus modelos de premiação são mostrados na figura 5. Estes indicadores se referem respectivamente a contratos de manutenção de analisadores ambientais, equipamentos de telecomunicações e bombas centrífugas. Através da figura 5 pode-se observar o funcionamento dos indicadores de desempenho. No que se refere ao índice de aumento de vida útil de bombas centrífugas, por exemplo, são estabelecidos valores 
extremos para a avaliação do desempenho da contratada com relação a este indicador. Se for constatada a redução da vida útil do equipamento, a empresa contratada deverá arcar com ônus de 5\% do valor total da manutenção realizada sobre o equipamento. Caso ocorra aumento de vida útil, a contratada será bonificada. Quanto maior o aumento de vida útil, maior o valor do bônus a ser recebido pela contratada, conforme figura 5.
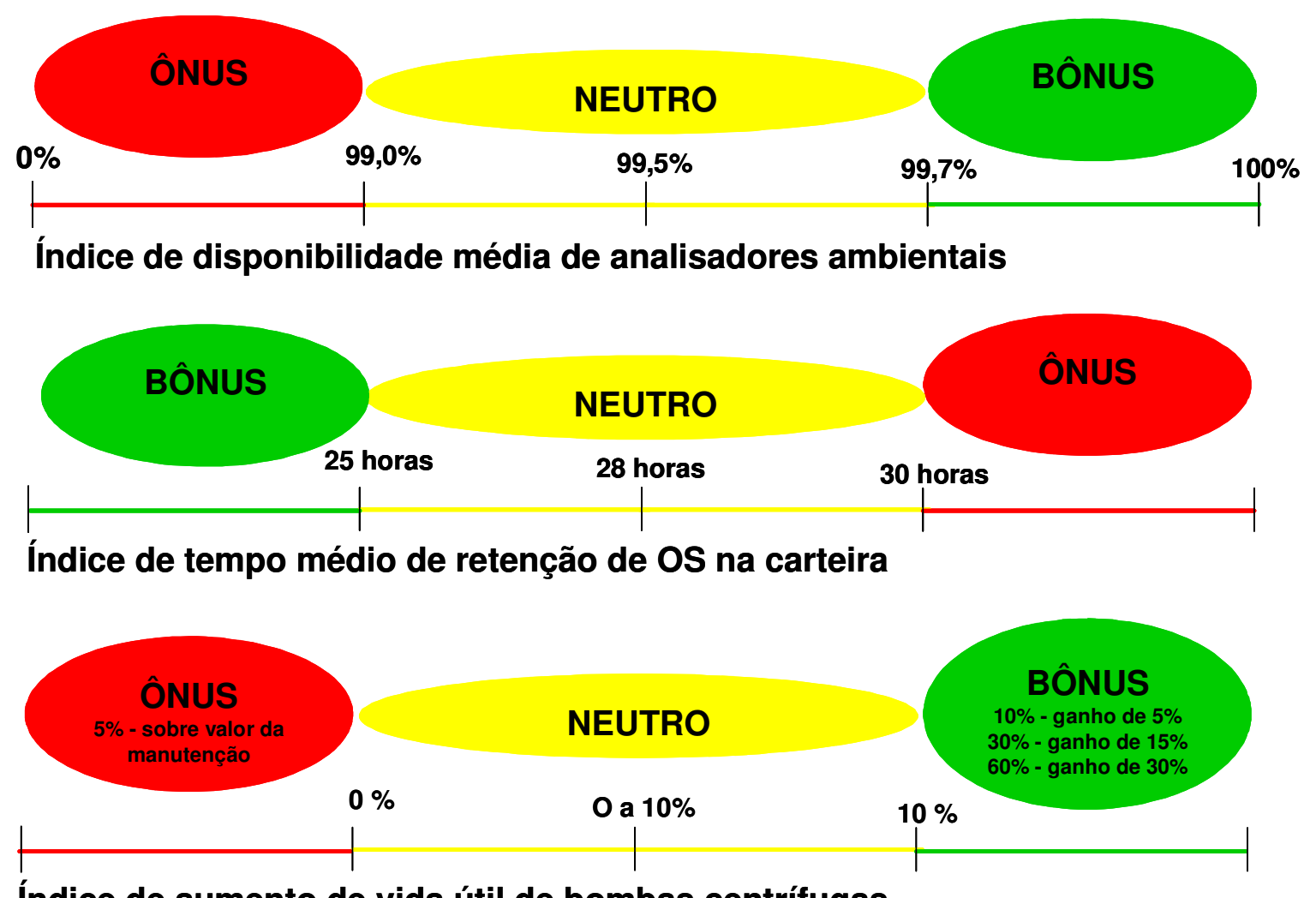

Índice de aumento de vida útil de bombas centrífugas

Figura 5: Exemplo de indicadores de desempenho utilizados na CST Arcelor Brasil Fonte: SANTOS (2005, p.9)

\section{CONCLUSÃO}

A manutenção industrial tem passado por mudanças, deixando de se preocupar apenas com o custo final, estando mais atenta aos indicadores de desempenho, com foco na disponibilidade de máquinas e eficiência operacional. O conceito de empreiteirização tem sido substituído pelo de parcerias estratégicas de longo prazo, onde os envolvidos são aliados na cadeia de valor. O modelo de contratação acompanha esta evolução, incluindo cláusulas de desempenho nas quais quanto maior a possibilidade de variação dos custos do projeto, mais 


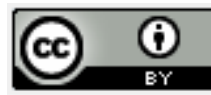

estimulador se torna este modelo de contratação. A contratação por desempenho exige desde o alinhamento estratégico da contratante à forma de gerenciamento dos contratos até a identificação de suas necessidades e seleção adequada de indicadores.

Na CST Arcelor Brasil, inicialmente, o conceito de contratação por desempenho despertava insegurança quanto ao seu impacto no processo operacional. Após cinco anos de aplicação deste conceito, os resultados obtidos foram satisfatórios tanto para a CST quanto para as empresas parceiras. Foram observados, dentre outros fatores, o aumento da disponibilidade de equipamentos, redução de custo de manutenção e materiais e melhorias na área de segurança do trabalho (SANTOS, 2005). Das cinco avaliações feitas no primeiro trimestre de 2006, três proporcionaram o pagamento de bônus e duas não receberam premiação nem foram penalizadas. Desta forma, este tipo de contratação trouxe vantagem competitiva para a CST e suas parceiras, conduzindo-as a especialização e à continuidade de seus negócios.

A Associação Brasileira de Manutenção, em sua pesquisa sobre a situação da manutenção no Brasil, identificou que em 2003, a contratação por resultados representava apenas 5,95\% dos contratos. Dentre as maiores dificuldades da implementação deste modelo está a definição dos indicadores e limites adequados dos resultados esperados. A contratação por resultado é recente no mercado mundial, não existindo muitos padrões de referência (GARCIA, 2005).

A contratação por desempenho, considerando-se sua complexidade e a realidade industrial brasileira, deverá ocorrer de forma lenta e gradual, iniciando-se por empresas de grande porte. Identifica-se como oportunidade de estudos e desenvolvimento, a criação de uma sistemática padronizada da contratação por desempenho, incluindo a classificação da criticidade dos serviços, seleção de parceiros e indicadores.

\section{REFERÊNCIAS}

GARCIA, Paulo C. \& LINHARES, A.Contratos de Terceirização de Manutenção Industrial Modalidade Risco: Análise das Expectativas do Setor Industrial e dos Provedores de Serviço. Revista de Administração Mackenzie. Ano 5, n.2, p. 79-98, 2005.

HALEN, Simone. Terceirização no Setor de RH: Estudo de Caso em Empresas do Setor Metal-Mecânico. f. 156. Dissertação (Mestrado em Administração).Universidade Federal do Rio Grande do Sul, Porto Alegre, 2000. 
PEDRIALI, Marcelle. Business Process Outsourcing: Uma Importante Ferramenta Estratégica da Terceirização. In: CONGRESSO BRASILEIRO DE CUSTOS, Porto Seguro, 2004. Disponível em: <http://www.abmcustos.org.br>. Acesso em: 16 dez. 2006.

PINTO, Luiz A. B. Manutenção por Contratação de Resultados. Revista Eletrônica da Universidade Tecnológica do Paraná, Ponta Grossa, 2004. Disponível em:<http://www.pg.cefetpr.br>. Acesso em:16 out.2006.

PIRES, Silvio R.I.Gestão da Cadeia de Suprimentos:Conceitos,Estratégias, Práticas e Casos. São Paulo: Atlas,2004.

SANTOS, Geraldo M. R. et al. Contratação de Serviços de Manutenção por Performance na CST. In: CONGRESSO BRASILEIRO DE MANUTENÇÃO, 2005, Belo Horizonte. Anais.

SÉDER, João L. M. A Terceirização Como Estratégia Logística para Ampliação de um Sistema de Compressão de Gás Natural numa Estação da Petrobrás. f. 123. Dissertação (Mestrado em Engenharia de Produção). Universidade Federal de Santa Catarina, Florianópolis, 2002.

SILVA, Eduardo G. T. Quebra de Paradigmas na Contratação de Serviços Terceirizados. In: . CONGRESSO BRASILEIRO DE MANUTENÇÃO, 2006, Aracaju. Anais.

SLACK, Nigel et al. Administração da Produção. São Paulo: Atlas, 2002.

SORMANI, Ferraz et al. Contratação por Performance para Serviços de Manutenção Industrial. In: CONGRESSO BRASILEIRO DE MANUTENÇÃO, 2005, Belo Horizonte. Anais.

SOUZA, Luiz R. C. \& SOUZA R. F. Contrato de Performance: Uma Parceria Bem Sucedida. In: CONGRESSO BRASILEIRO DE MANUTENÇÃO, 2005, Belo Horizonte. Anais. 